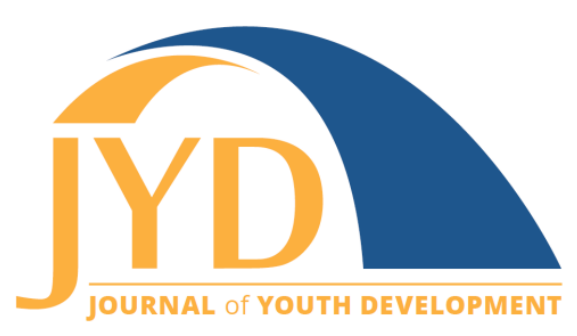

http://jyd.pitt.edu/ | Vol. 15 Issue 6 DOI 10.5195/jyd.2020.919 | ISSN 2325-4017 (online)

\title{
Resource Review: Breakout EDU
}

\author{
Rachel Bayer \\ University of Maryland Extension \\ rachel.bayer@usda.gov \\ Catherine Sorenson \\ University of Maryland Extension \\ cjrsoren@umd.edu
}

\begin{abstract}
Game-based learning is becoming an increasingly popular pedagogical technique for providing engaging learning experiences for youth. The Breakout EDU platform provides an opportunity to bring game-based learning into formal and non-formal learning environments using an escape-room-like approach while teaching specific subject areas and building life skills. There are more than 1,500 ready-made games for teaching a variety of topic areas, from science and math to team building, in any learning context. It also provides resources and tools to support youth development professionals in creating their own games. This review provides an overview of Breakout EDU and its kit and digital platform components and offers considerations for youth development professionals.
\end{abstract}

Key words: game-based learning, Breakout EDU, gamification, escape rooms

\section{Introduction}

Escape rooms, live-action social games requiring groups to work together to solve a series of puzzles in a period of time (Nicholson, 2018; Rouse, 2017), are becoming a popular gamebased learning strategy for the classroom (Mayer \& Toates, 2016). Game-based learning, which is the application of self-contained games in an educational context to meet learning objectives, is a growing trend in education (O'Brien \& Pitera, 2019). Research suggests that digital gamebased learning can improve academic achievement and learning attitudes for many subjects including English, science, math, and social studies (Lin et al., 2013; Partovi \& Reza, 2019; Rouse, 2017).

(cc) EY New articles in this journal are licensed under a Creative Commons Attribution 4.0 License. This journal is published by the University Library System, University of Pittsburgh and is cosponsored by the University of Pittsburgh Press. The Journal of Youth Development is the official peer-reviewed publication of the National Association of Extension 4-H Youth Development Professionals and the National AfterSchool Association. 
Current literature focuses on using escape rooms in post-secondary environments to study topics such as sport and exercise science (Humphrey, 2017), medicine (Wu et al., 2018), pharmacy (Eukel et al., 2017), and information/research literacy (Pun, 2017; O'Brien \& Pitera, 2019), as well as with high school chemistry students (Nguyen, 2018). This literature suggests that youth engagement in escape rooms can develop "soft skills," including cooperation, communication, leadership, collaboration, critical thinking, teamwork, and problem-solving skills (Humphrey, 2017; Nicholson, 2018; O'Brien \& Pitera, 2019; Rouse, 2017; Wu et al., 2018). Use of escape rooms may provide youth development professionals with a unique way to develop these life skills in youth.

\section{Breakout EDU}

Breakout EDU is open-source technology, created by two educators, providing game-based learning around the escape room concept. Individuals work together to solve various puzzles to unlock and "break out" (by opening) of their Breakout EDU box (Rouse, 2017).

\section{Description}

Breakout EDU offers a kit for purchase that contains boxes, a series of locks, and other tools. It also has an online digital gaming platform providing more than 1,500 games for use with the kit or on their own.

\section{Digital Gaming Platform}

The Breakout EDU digital gaming platform contains games that teach a variety of subject areas, instructions for kit use, a digital games creator, and additional resources. Breakout EDU professionals or users design the games on the platform. The platform includes games that rely solely on the kit, digital games played on their platform using an electronic device, and hybrid games that rely on both the kit and digital elements.

Games on a specific topic or subject area can be found by using the platform's search engine or browsing by topic area. Table 1 outlines how the platform organizes games by topic areas and then subject. Each subject contains numerous games. 
Journal of Youth Development | http://jyd.pitt.edu/ | Vol. 15 Issue 6 DOI 10.5195/jyd.2020.919

Resource Review: Breakout EDU

Table 1. Breakout EDU Topic Areas and Accompanying Subjects

\begin{tabular}{|c|c|}
\hline Topic area & Subjects \\
\hline The Arts & Arts \& Music \\
\hline Career Technical Education & Career Technical Education \\
\hline Computer Science & Computer Science \\
\hline Holiday/Seasonal & $\begin{array}{l}\text { Halloween } \\
\text { Thanksgiving } \\
\text { Winter Holidays } \\
\text { Other Holidays }\end{array}$ \\
\hline Language & $\begin{array}{l}\text { English Language Arts } \\
\text { Foundational English Language Arts } \\
\text { French } \\
\text { Global Read Aloud } \\
\text { Literature } \\
\text { Spanish }\end{array}$ \\
\hline Library & Library Science \\
\hline Math & $\begin{array}{l}\text { Algebra } \\
\text { Foundational Math } \\
\text { Geometry } \\
\text { Pre-Algebra }\end{array}$ \\
\hline Physical Education & Physical Education \\
\hline Science & $\begin{array}{l}\text { Biology } \\
\text { Chemistry } \\
\text { Earth Science } \\
\text { Foundational Science } \\
\text { Physics }\end{array}$ \\
\hline Social Studies & $\begin{array}{l}\text { Foundational Social Studies } \\
\text { U.S. History } \\
\text { World History }\end{array}$ \\
\hline
\end{tabular}


Table 1. (continued)

\begin{tabular}{|l|l|}
\hline Topic area & Subjects \\
\hline Team Building & Team Building \\
\hline Elementary & $\begin{array}{l}\text { Elementary Computer Science } \\
\text { Early Elementary } \\
\text { Elementary Language } \\
\text { Elementary Math } \\
\text { Elementary Science } \\
\text { Elementary Social Studies } \\
\text { Elementary Team Building }\end{array}$ \\
\hline
\end{tabular}

Games have detailed lesson plans containing a background story, a list of lock combinations, video (or written) directions for setting up and running the game, links for printouts, and reflection questions.

In addition, each game has an overview telling the user the game's content area, ideal group size, recommended ages/grade levels, and national curricula standards alignments. Most games using the kit are designed to be completed in an hour or less. The digital games have more variation in the time required.

\section{Kits}

The Breakout EDU kit is a set of game materials requiring that students work together to solve various puzzles and open a locked box, similar to an escape room. One or more locks may secure a box, the combinations for which must be determined through game play. The included locks are unique in that they can be reset and used repeatedly for new games. Each kit typically can be used by 8 to 12 individuals during a game. Table 2 describes the Breakout EDU kit components and provides pictures of each. 
Table 2. Breakout EDU Kit Component Descriptions and Pictures

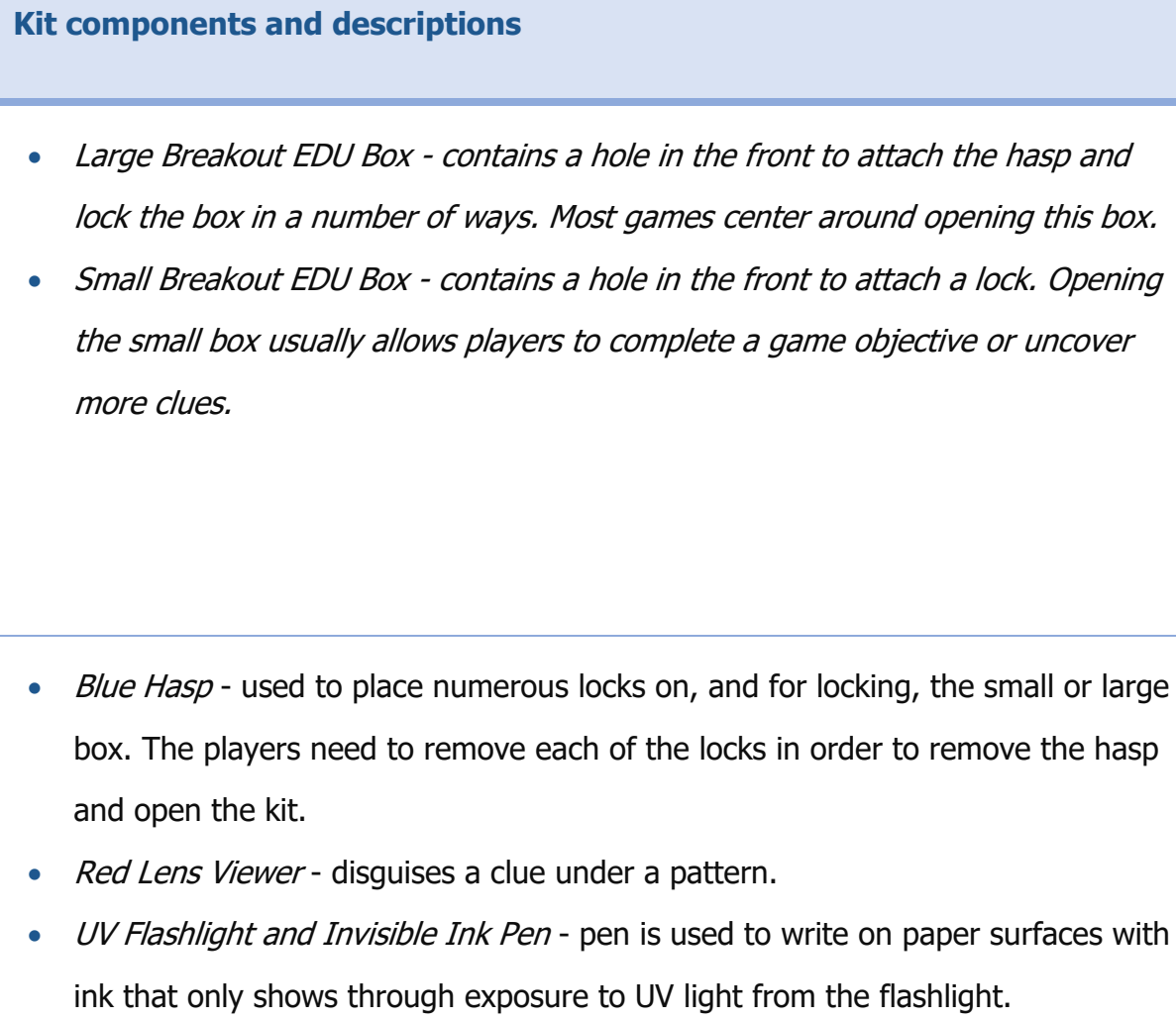

- Large Breakout EDU Box - contains a hole in the front to attach the hasp and lock the box in a number of ways. Most games center around opening this box.

- Small Breakout EDU Box - contains a hole in the front to attach a lock. Opening the small box usually allows players to complete a game objective or uncover more clues.

- Blue Hasp - used to place numerous locks on, and for locking, the small or large box. The players need to remove each of the locks in order to remove the hasp and open the kit.

- Red Lens Viewer - disguises a clue under a pattern.

- UV Flashlight and Invisible Ink Pen - pen is used to write on paper surfaces with ink that only shows through exposure to UV light from the flashlight.

Key Lock, 4-Digit Lock, and 3-Digit Lock- used to lock the boxes or to be locked on the hasp. The digit locks can be reset.

Multilock (two contained in each kit) - this lock is unique to Breakout EDU and allows users to create their own combinations with locks that have removable and interchangeable wheels. There are color, letter, number, and directional wheels for the multilocks.

- 2 Hint Cards - used by players of the game to receive a hint when needed in the game.

- USB Drive - used to load files for games requiring digital elements.

- Reflection Cards - used to help players reflect on their experience, what they learned, and how they worked as a group.
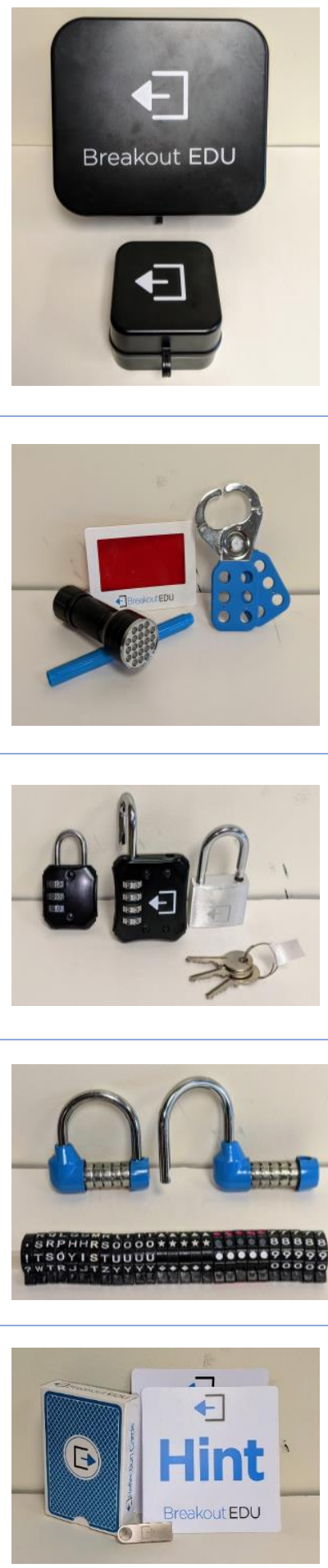


\section{Considerations for Youth Development Professionals}

The Breakout EDU platform provides an innovative game-based learning opportunity for youth development professionals. Below are considerations for using this resource.

- The kit is designed for use by 8 to 12 individuals, so larger groups may require multiple kits as well as additional facilitators to help oversee the game play.

- In our experience using the kit, individuals may want to pre-set the room and test the locks prior to implementing the game. We recommend testing the game with colleagues or others, especially for anyone new to using escape rooms with youth.

- Most games have rules regarding time limit, location where participants can go, use of hints, and things in the room they can disturb. Locks can be accidently re-set by participants, so facilitators should collect opened locks.

- It is important to have a "prize" for youth upon opening the box, such as a "you won" sign, as opening an empty box is anticlimactic.

- The platform provides resources for creating games to teach specific subjects but creating them may be time intensive. However, the many pre-made games on the platform provide youth development professionals with a time-efficient way to teach a variety of subjects.

- When using Breakout EDU, youth development professionals should serve as facilitators of learning, encouraging youth collaboration and providing hints as needed as opposed to providing the answer (O'Brien \& Pitera, 2019). Ensuring learning objectives are met requires engaging and supporting youth during the game play through the use of a storyline, hints, rewards, and verbal encouragement (Martens \& Crawford, 2019; Nicholson, 2018).

- In order to achieve learning goals, it is important for youth to reflect upon their experience as a group, discussing what they learned and found interesting or difficult (O'Brien \& Pitera, 2019; Rouse, 2017). In addition, scaffolding instruction using pre and post activities (such as reflection) can also improve learning outcomes (O'Brien \& Pitera, 2019).

For youth development professionals interested in integrating escape rooms into their programming, Breakout EDU offers a low-cost and accessible option for doing so in a fun and engaging way. 


\section{How to Obtain}

Free Breakout EDU accounts provide access to user-generated games and a few featured Breakout EDU Digital Games. The online platform with complete access can be purchased for $\$ 75$ to $\$ 100$ annually. The Breakout EDU kit costs $\$ 150$ and includes a 12-month subscription code to the online platform. Both can be purchased at https://store.breakoutedu.com/. Paid accounts have access to all the curricula, standards-aligned games, and subject packs designed by the professional Breakout EDU team and the Breakout EDU Digital Game Creator.

\section{References}

Eukel, H. N., Frenzel, J. E., \& Cernusca, D. (2017). Educational gaming for pharmacy students - design and evaluation of a diabetes-themed escape room. American Journal of Pharmaceutical Education. 81(7), Article 6265. https://doi.org/10.5688/ajpe8176265

Humphrey, K. (2017). The application of a serious, non-digital escape game learning experience in higher education. Sport \& Exercise Psychology Review. 13(2), 48-54.

Lin, C.-H., Liu, E. Z.-F., Chen Y.-L., Liou, P.-Y., Chang, M., Wu, C.-H., \& Yuan, S.-M. (2013). Game-based remedial instruction in mastery learning for upper-primary school students. Educational Technology \& Society, 16(2), 271-281.

Martens, S., \& Crawford, K. (2019). Embracing wonder and curiosity: Transforming teacher practice through escape room design. Childhood Education, 95(2), 68-75. https://doi.org/10.1080/00094056.2019.1593764

Mayer, B., \& Toates, L. (2016). Great escapes: Escape room games use problem solving skills to boost curriculum. School Library Journal, 62(10), 14-15.

Nguyen, T. (2018). Moving from classroom to escape room. C\&EN, 96(19), 28-30. https://doi.org/10.1021/cen-09619-feature4

Nicholson, S. (2018). Creating engaging escape rooms for the classroom. Childhood Education, 94(1), 4449. https://doi.org/10.1080/00094056.2018.1420363

O'Brien, K., \& Pitera, J. (2019). Gamifying instruction and engaging students with Breakout EDU. Journal of Educational Technology Systems, 48(2), 192-212. https://doi.org/10.1177/0047239519877165

Partovi, T., \& Reza, M. (2019). The effect of game-based learning on academic achievement motivation of elementary school students. Learning \& Motivation, 68, Article 101592.

\section{https://doi.org/10.1016/j.Imot.2019.101592}

Pun, R. (2017). Hacking the research library: Wikipedia, Trump, and information literacy in the escape room at Fresno State. Library Quarterly: Information, Community, Policy, 874), 330-336.

\section{https://doi.org/10.1086/693489}


Journal of Youth Development | http://jyd.pitt.edu/ | Vol. 15 Issue 6 DOI 10.5195/jyd.2020.919

Resource Review: Breakout EDU

Rouse, W. (2017). Lessons learned while escaping from a zombie: Designing a Breakout EDU game. The History Teacher, 50(4), 553-564.

Wu, C., Wagenshutz, H., \& Hein, J. (2018). Promoting leadership and teamwork development through escape rooms. Medical Education, 52(5), 561-562. https://doi.org/10.1111/medu.13557 